\title{
Solid and gaseous cerebral microembolization after biologic and mechanical aortic valve replacement: Investigation with multirange and multifrequency transcranial Doppler ultrasound
}

Lorenzo Guerrieri Wolf, MD, Bikram P. Choudhary, MRCS, Yasir Abu-Omar, MRCS, and David P. Taggart, MD (Hons), PhD, FRCS

From the Department of Cardiothoracic Surgery, John Radcliffe Hospital, Oxford, United Kingdom.

Received for publication March 17, 2007; revisions received July 8, 2007; accepted for publication July 10, 2007.

Address for reprints: David P. Taggart, MD (Hons), PhD, FRCS, Professor of Cardiovascular Surgery (University of Oxford), Department of Cardiothoracic Surgery, John Radcliffe Hospital, Headley Way, Headington, Oxford OX3 9DU, United Kingdom (E-mail: david.taggart@orh.nhs. uk).

J Thorac Cardiovasc Surg 2008;135:512-20 $0022-5223 / \$ 34.00$

Copyright () 2008 by The American Association for Thoracic Surgery

doi:10.1016/j.jtcvs.2007.07.062
Objective: Cerebral microembolization is a well-recognized phenomenon after cardiac valve replacement, but the relative proportion of solid and gaseous emboli is uncertain. Particulate microemboli are thought to be the most damaging. With the use of multifrequency transcranial Doppler ultrasound, we compared the number and nature of microemboli in recipients of biologic and mechanical aortic valve prostheses.

Methods: The middle cerebral arteries of 60 patients were monitored bilaterally with a new-generation transcranial Doppler ultrasound (Embo-Dop, DWL Elektronische Systeme GmbH, Singen, Germany) that rejects artefacts online and automatically discriminates between solid and gaseous microemboli. All recordings were performed during a 30-minute period 1 day before and at a mean of 5 days and 3 months after isolated aortic valve replacement with a biologic (30, group B) or mechanical (30, group $\mathrm{M})$ prosthesis.

Results: The patients in group B were older, with a mean age of $70.6 \pm 9.7$ years versus $55.4 \pm 9.4$ years $(P<.005)$ in the patients in group M. Biologic prosthesis recipients were all taking aspirin (no warfarin); patients with mechanical valves were well anticoagulated with warfarin both 5 days and 3 months after surgery. None of the patients had solid microemboli preoperatively. Five days postoperatively, the absolute number of cerebral microemboli was 145 and 594 for total microemboli $(P=.001)$ and 41 and 182 for solid microemboli $(P=.002)$ in groups B and $\mathrm{M}$, respectively. At 3 months, the absolute number was 65 and 608 for total microemboli $(P<.001)$ and 10 and 188 for solid microemboli $(P<.001)$ in groups $\mathrm{B}$ and $\mathrm{M}$, respectively. Solid microemboli accounted for $16 \%$ of the total microembolic load in group B compared with $31 \%$ in group $\mathrm{M}(P=.05)$ at 3 months.

Conclusions: Solid cerebral microemboli represent approximately one third of the total cerebral microembolic load after mechanical aortic valve replacement and are detectable in the majority of such patients both 5 days and 3 months after surgery. The neurofunctional consequences of this phenomenon should be carefully assessed.

$\mathrm{S}$ ince the first detection of intracavitary echoes in prosthetic heart valves in $1975,{ }^{1}$ several studies have reported transcranially detected high intensity transient signals (HITS) in patients with a normally functioning heart valve prosthesis, including mechanical, ${ }^{2-9}$ bioprosthetic, ${ }^{6,7,10}$ homograft,,${ }^{11}$ and pulmonary autograft ${ }^{12}$ recipients, implying cerebral microembolization. 


\section{Abbreviations and Acronyms \\ $\mathrm{AVR}=$ aortic valve replacement \\ HITS $=$ high intensity transient signals \\ MCA $=$ middle cerebral artery \\ TCD $=$ transcranial Doppler}

Intraoperative cerebral microembolization is considered to be an important cause of postoperative neurocognitive decline in cardiac surgery. ${ }^{13-16}$ This finding is supported by our own recent demonstration of a correlation between the number of intraoperative cerebral microemboli and the subsequent impairment of verbal memory defined by functional magnetic resonance imaging of the brain in patients undergoing coronary artery bypass grafting. ${ }^{17,18}$ Although there is previous $^{2,19}$ and more recent ${ }^{9}$ evidence that a higher HITS count is associated with worse neuropsychologic outcome, there is also evidence that HITS after valve replacement have no correlation with neuropsychologic outcome. ${ }^{6,20-22}$ Consequently, any postulated correlation between neurocognitive damage and ongoing postoperative cerebral microemboli production in heart valve prosthesis recipients must be regarded as controversial.

Microembolization after valve replacement is a multifactorial and complex process. It is thought to be caused mainly by high hemodynamic stresses at the valvular level ${ }^{22}$ as a consequence of high energy dissipation at valve closure ${ }^{23}$ and extremely low pressure zones on the inflow side of mechanical heart valves. ${ }^{24}$ This is exaggerated by turbulent blood flow downstream from prosthetic valves ${ }^{22,24}$ leading to the formation of nitrogen and oxygen gas bubbles and/or thrombocyte aggregates, which are subsequently recorded in the cerebral circulation as HITS. Prosthetic valve de$\operatorname{sign}^{6,24-26}$ and orientation ${ }^{26}$ influence both shear rates and the grade of blood flow turbulence and are thought to have an important impact on the formation of such microemboli. Other factors (patient's age, ${ }^{22}$ myocardial contractility, ${ }^{27}$ heart rate, ${ }^{27}$ method of valve implantation, ${ }^{28}$ valve dysfunction, ${ }^{29}$ acetylsalicylate infusion, ${ }^{3,24}$ oxygen therapy, ${ }^{5,7,21,24,30}$ hyperbaric oxygen ${ }^{8}$ ) have also been found to influence HITS rate after prosthetic valves replacement.

The composition of cerebral microemboli in recipients of prosthetic valves has previously been suspected from various indirect evidence $\left(\mathrm{O}_{2}\right.$, hyperbaric $\mathrm{O}_{2}$, antiplatelet agents). Although particulate microemboli are likely to be more damaging than gaseous microemboli, a closer correlation between solid cerebral microembolization and neurocognitive decline might be anticipated. Several articles ${ }^{31,32}$ have also dealt with the issue of the potential damaging effects of gaseous microemboli.

In the present study, a new-generation transcranial Doppler (TCD) ultrasound ${ }^{33,34}$ that rejects artefacts online and automatically discriminates between solid and gaseous microemboli was used to compare the number and nature of microemboli in patients with biological and mechanical aortic valve prostheses early and late after operation in an attempt to determine the exact proportion of particulate microemboli.

\section{Materials and Methods}

A total of 60 patients admitted to the John Radcliffe Hospital for elective isolated aortic valve replacement (AVR) were prospectively recruited for the study. All patients gave informed consent, and full ethical approval was obtained from the local research ethics committee (Oxford Research Ethics Committee number C01.258).

The patients were divided into 2 groups. Thirty patients underwent isolated AVR with biological prostheses (group B), and 30 patients underwent isolated AVR with mechanical prostheses (group M). Patients with symptomatic carotid disease, peripheral vascular disease, preoperative neurologic history, or atrial fibrillation were excluded. Methods of valve implantation included the interrupted suture technique with positioning of subannular pledgets and the continuous suture technique with six 2-0 polypropylene sutures. Methods of myocardial protection, cardiopulmonary bypass, aortotomy, valve excision, and debridement were similar in all of the study patients. Transesophageal echocardiography was used routinely in all study patients to demonstrate normal function and seating of the valve and to confirm adequate deairing. All mechanical valves were implanted in their optimum orientation. ${ }^{35}$ All patients had a well-functioning aortic prosthesis as demonstrated by echocardiography at the times when the TCD studies were conducted. By the fourth postoperative day, none of the patients were receiving supplemental oxygen.

\section{Transcranial Doppler Monitoring}

Bilateral TCD monitoring of the middle cerebral arteries for a continuous period of 30 minutes was performed in all patients 1 day before the operation and at a mean of 5 days ( $5 \pm 1$ days in group B and $5.5 \pm 1.3$ days in group $\mathrm{M}$ ) and 3 months $(90 \pm 14$ days in group B and $90 \pm 7$ days in group $\mathrm{M})$ after surgery.

All recordings of the middle cerebral artery (MCA) were performed bilaterally using a multirange, multifrequency TCD (Embo-Dop; DWL Elektronische Systeme GmbH, Singen, Germany), which rejects artefacts online and automatically discriminates between solid and gaseous microemboli. ${ }^{33,34}$ We previously described this new-generation equipment. ${ }^{17}$ In brief, we simultaneously insonated the MCAs bilaterally through dual-frequency probes (2.0 and $2.5 \mathrm{MHz}$ ) fixed to the transtemporal windows above the right and left zygomatic arches using a specifically designed head brace. An additional $2.0-\mathrm{MHz}$ insonation reference 
gate was set $15 \mathrm{~mm}$ superficially to the MCA insonation gate whose depth was set between 45 and $55 \mathrm{~mm}$ with a sample volume of $13 \mathrm{~mm}$. The multifrequency system (2.0 $\mathrm{MHz}$ and $2.5 \mathrm{MHz}$ ) serves for the automatic microemboli nature discrimination: Gaseous microemboli reflect more ultrasound at lower frequencies than at higher frequencies, contrary to what occurs in the case of solid microemboli. The reference gate serves for the online rejection of artifacts: The latter are identified when HITS are detected in both gates (MCAs and reference gates) simultaneously or with a time delay of less than $4 \mathrm{msec}$.

\section{Statistical Analysis}

Patient characteristics are presented as mean \pm standard deviation or percentage of the total. The number of microemboli is presented as the absolute number and the median and 25th to 75th percentiles. Statistical comparison, for normally distributed data, was performed using the Student $t$ test for continuous variables and the chi-square test or Fisher exact test (as appropriate) for categoric variables. Because the data for the number of microemboli were not normally distributed, the nonparametric Mann-Whitney $U$ test was used to compare the difference among the 2 groups. The Wilcoxon test was used to analyze the variation of the number of microemboli over time within each group. A stepwise logistic regression analysis was performed to select predictors of HITS; the model was built using variables that demonstrated a $P$ value less than .10 in the univariate analysis. The significance within the model was evaluated with the Wald statistical test. The Statistical Package for the Social Sciences version 12.0 (SPSS Inc, Chicago, Ill) software was used for statistical calculations.

\section{Results}

Patients in group B (22 male, 8 female) were older than those in group M (23 male, 7 female), with a mean age of $70.6 \pm 9.7$ years versus $55.4 \pm 9.4$ years $(P<.005)$. All other demographic and preoperative patient characteristics were similar in the 2 groups and are summarized in Table 1. Operative and postoperative data are shown in Table 2. Biological prosthesis recipients all received aspirin (no warfarin); patients with mechanical valves all received oral anticoagulants with a mean international normalized ratio in the therapeutic range $(2.8 \pm 0.6)$ both 5 days and 3 months after surgery. The types of valve prostheses implanted in the study patients are summarized in Table 3 .

\section{Microemboli}

Twenty percent of patients in both groups were positive for HITS before the operation, but none were solid microemboli. The relative frequency of patients positive for HITS was significantly higher in mechanical heart valve prosthesis recipients than in biological recipients both 5 days and 3
TABLE 1. Demographic and preoperative patient characteristics

\begin{tabular}{lccc}
\hline Characteristics & Group B & Group M & P value \\
\hline No. & 30 & 30 & - \\
Age, y (mean \pm SD) & $70.6 \pm 9.7$ & $55.4 \pm 9.4$ & $<.005$ \\
Females, n (\%) & $8(27)$ & $7(23)$ & .76 \\
Parsonnet score (mean & $7.9 \pm 7$ & $8.5 \pm 6.6$ & .71 \\
$\quad \pm$ SD) & & & \\
EURO score (mean \pm & $3.4 \pm 2.1$ & $3.4 \pm 2.4$ & .96 \\
$\quad$ SD) & & & \\
EF, \% (mean \pm SD) & $52.7 \pm 8$ & $54 \pm 7$ & .73 \\
Diabetes, n (\%) & $3(10)$ & $1(3)$ & .3 \\
Hypertension, n (\%) & $19(63)$ & $15(50)$ & .29 \\
Smoking, n (\%) & $19(63)$ & $16(53)$ & .43 \\
Previous MI, n (\%) & $0(0)$ & $0(0)$ & - \\
Previous CVA/TIA, n & $0(0)$ & $0(0)$ & - \\
$\quad$ (\%) & & & \\
PVD, n (\%) & $0(0)$ & $0(0)$ & - \\
AF, n (\%) & $0(0)$ & $0(0)$ & - \\
AS, n (\%) & $19(63)$ & $21(70)$ & .58 \\
AR, n (\%) & $4(13)$ & $4(13)$ & 1 \\
AS/AR, n (\%) & $7(24)$ & $5(17)$ & .51 \\
Degenerative, n (\%) & $20(67)$ & $15(50)$ & .19 \\
Congenital, ${ }^{*} \mathrm{n}(\%)$ & $8(27)$ & $11(37)$ & .4 \\
Endocarditis, $\dagger \mathrm{n}(\%)$ & $2(6)$ & $4(13)$ & .38 \\
Rheumatic, n (\%) & $0(0)$ & $0(0)$ & - \\
\hline SD, Standard devation; EF, & & & - \\
\hline
\end{tabular}

$S D$, Standard deviation; $E F$, ejection fraction; $M I$, myocardial infarction; CVA/TIA, cerebrovascular accident/transient ischemic attack; $P V D$, peripheral vascular disease; $A F$, atrial fibrillation; $A S$, aortic stenosis; $A R$, aortic regurgitation; $A S / A R$, mixed pathology (stenosis plus regurgitation). *Bicuspid valve. TSequelae of healed infective endocarditis.

months after surgery. An even more marked difference between the 2 groups was evident for solid microemboli. The percentage of bioprostheses recipients who were positive for solid microemboli decreased significantly over time $(P=.01)$, but this did not occur in those with mechanical valves (Table 4).

A similar small amount of total microemboli were detected in biological and mechanical aortic valve prostheses recipients before the operation. At 5 days and 3 months after surgery the median number (25th-75th percentile) of any microemboli (Figure 1) and solid microemboli (Figure 2) was significantly higher in mechanical recipients than biological recipients. Figures 1 and 2 show that the median number (25th-75th percentile) of any and solid microemboli decreased significantly over time in biological recipients, with a steady production of HITS in patients with mechanical valves. Although a similar proportion of solid microemboli was found between the 2 groups early postoperatively, at 3 months after surgery the proportion of particulate microemboli was significantly higher in group $\mathrm{M}$ than in group B (Table 4).

In the multivariate analysis, increased heart rate and the implantation of mechanical valve prosthesis were signifi- 
TABLE 2. Operative and postoperative data

\begin{tabular}{lccc}
\hline Data & Group B & Group M & $P$ value \\
\hline CPB time, min (mean \pm SD) & $74.1 \pm 6$ & $73.8 \pm 5.8$ & .84 \\
Crossclamp time, min (mean & $61.3 \pm 6.3$ & $61.2 \pm 6$ & .94 \\
$\quad \pm$ SD) & & & \\
Method of valve implantation & & & \\
Subannular pledgets, n (\%) & $22(73)$ & $25(83)$ & .34 \\
Continuous suture, n (\%) & $8(27)$ & $5(17)$ & .34 \\
Valve size, mm (mean \pm SD) & $23.1 \pm 1.9$ & $23.8 \pm 2.2$ & .17 \\
Valve type & & & \\
Bileaflet, n (\%) & - & $30(100)$ & - \\
Tilting disc, n (\%) & - & $0(0)$ & - \\
Early-late postoperative EF & & & \\
Good, n (\%) & $16(54)$ & $17(57)$ & .79 \\
Fair, n (\%) & $10(33)$ & $9(30)$ & .78 \\
Poor, n (\%) & $4(13)$ & $4(13)$ & 1 \\
Early postoperative HR, & $73.3 \pm 12$ & $74 \pm 12.5$ & .82 \\
$\quad$ (mean \pm SD) & & & \\
Late postoperative HR, & $73.5 \pm 12$ & $74 \pm 12$ & .82 \\
$\quad$ (mean \pm SD) & & & \\
Early-late $\beta$-blockade, n (\%) & $6(20)$ & $8(27)$ & .54 \\
\hline
\end{tabular}

$C P B$, Cardiopulmonary bypass; $S D$, standard deviation; $E F$, ejection fraction (good $>50 \%$, fair $>40 \%<50 \%$, poor $<40 \%)$; $H R$, heart rate.

cantly associated with an increased number of HITS $(P=$ .02 and $P=.003$, respectively). We did not find an association with patient age.

\section{Discussion}

To our knowledge, this is the first report to use a multifrequency TCD to directly compare the number and nature of cerebral microemboli in such a large cohort of biologic and mechanical aortic valve prostheses recipients. The main finding of this study was that solid microemboli represented approximately one third of the total cerebral microembolic load after mechanical AVR and were detectable in the majority of such patients both 5 days (80\%) and 3 months (93\%) after surgery. In addition, the present study demonstrated that gaseous but not solid microemboli were detectable in approximately $20 \%$ of patients with aortic valvular disease before surgery, presumably because of the turbulence generated by a severely diseased valve, and that microembolic signals occur in most patients after both mechanical and biologic valve replacement in the early postoperative period. However, 3 months after surgery there was a reduction in the number of HITS in bioprosthesis recipients but a constant number in patients with a mechanical prosthesis. Moreover, although a minority of patients with bioprostheses experienced solid cerebral microembolization both 5 days and 3 months after surgery, the proportion of these patients who were positive for solid microemboli decreased over time. Finally, in accordance with previous observations, ${ }^{5,8,36-39}$ we found that the majority of
TABLE 3. Type of valve prosthesis implanted in the study patients

\begin{tabular}{|c|c|c|}
\hline Group & Prosthesis & Patients (n) \\
\hline \multirow[t]{5}{*}{$\mathrm{M}$} & $\begin{array}{l}\text { ATS (ATS Medical Inc, Minneapolis, } \\
\text { Minn) }\end{array}$ & 17 \\
\hline & $\begin{array}{l}\text { MIRA (Edwards Lifesciences, Irvine, } \\
\text { Calif) }\end{array}$ & 7 \\
\hline & $\begin{array}{l}\text { CarboMedics standard } \\
\text { (CarboMedics Inc, Austin, Tex) }\end{array}$ & 2 \\
\hline & $\begin{array}{l}\text { CarboMedics Top Hat (CarboMedics } \\
\text { Inc) }\end{array}$ & 2 \\
\hline & $\begin{array}{l}\text { St Jude Medical standard (St Jude } \\
\text { Medical Inc, St Paul, Minn) }\end{array}$ & 2 \\
\hline \multirow[t]{6}{*}{ B } & $\begin{array}{l}\text { EL standard (Edwards Lifesciences, } \\
\text { Irvine, Calif) }\end{array}$ & 13 \\
\hline & $\begin{array}{l}\text { Mosaic (Medtronic Inc., } \\
\text { Minneapolis, Minn) }\end{array}$ & 7 \\
\hline & $\begin{array}{l}\text { Aspire aortic (NoraMedica, } \\
\text { Copenhagen, Denmark) }\end{array}$ & 3 \\
\hline & $\begin{array}{l}\text { EL Perimount (Edwards Lifesciences, } \\
\text { Irvine, Calif) }\end{array}$ & 1 \\
\hline & $\begin{array}{l}\text { Mitroflow (CarboMedics Inc., Austin, } \\
\text { Tex) }\end{array}$ & 5 \\
\hline & $\begin{array}{l}\text { 3F (stentless) (3F Therapeutics, Lake } \\
\text { Forest, Calif) }\end{array}$ & 1 \\
\hline
\end{tabular}

microemboli were gaseous in nature, with solid microemboli accounting for a percentage of total microembolic load ranging between $16 \%$ (in biological prosthesis recipients, 3 months after surgery) and $31 \%$ (in mechanical prosthesis recipients, both 5 days and 3 months after surgery).

Discrimination between solid and gaseous microemboli in patients with prosthetic heart valves may have important pathophysiologic, therapeutic, and prognostic implications. The likely nature of cerebral microemboli in such patients has been investigated in the past with differing methods (Table 5). By performing simultaneous ultrasound monitoring, Georgiadis and colleagues ${ }^{36}$ reported a significantly higher number of HITS in the common carotid artery compared with those of the ipsilateral middle and anterior cerebral arteries in patients with artificial heart valves, arguing that as bubbles implode with time, the majority of the HITS were likely to be explained by gaseous emboli, consistent with previous spectral characteristic analysis of HITS. ${ }^{39}$ A similar conclusion was reached by Baumgartner and colleagues ${ }^{8}$ after demonstrating an increase in HITS in 15 mechanical valve recipients subjected to an increase in their environmental pressure. On the other hand, others ${ }^{3,24,40-42}$ have provided plausible evidence about the likely solid nature of at least some microemboli. Geiser and colleagues, ${ }^{41}$ using morphologic and functional methods, including flow cytometry and platelet-specific antibodies, reported an increased microembolic load and the presence of 
TABLE 4. Percentage of patients positive for any and solid microemboli, absolute number of any microemboli, and proportion of solid and gaseous microemboli detected 1 day before and 5 days and 3 months after isolated aortic valve replacement

\begin{tabular}{|c|c|c|c|c|c|c|}
\hline \multirow[b]{2}{*}{ Time at recording } & \multirow[b]{2}{*}{ Group } & \multicolumn{2}{|c|}{ Total patients } & \multicolumn{3}{|c|}{ Microemboli } \\
\hline & & $\begin{array}{c}\text { With any microemboli } \\
n(\%)\end{array}$ & $\begin{array}{l}\text { With solid microemboli } \\
\text { n (\%) }\end{array}$ & $\begin{array}{c}\text { Any } \\
\text { n }\end{array}$ & Gaseous n (\%) & Solid n (\%) \\
\hline \multirow[t]{2}{*}{ Preoperatively } & B & $6(20)$ & $0(0)$ & 26 & $26(100)$ & $0(0)$ \\
\hline & $M$ & $6(20)$ & $0(0)$ & 15 & $15(100)$ & $0(0)$ \\
\hline \multirow[t]{2}{*}{$5 \mathrm{~d}$ postoperatively* } & $B$ & $21(70)$ & $12(40) \ddagger$ & 145 & $104(72)$ & $41(28)$ \\
\hline & $M$ & $29(97)$ & $24(80)$ & 594 & 412 (69) & $182(31)$ \\
\hline \multirow[t]{2}{*}{3 mo postoperatively $†$} & $B$ & $18(60)$ & $4(13) \ddagger$ & 65 & $55(84)$ & $10(16)$ \\
\hline & M & $29(97)$ & $28(93)$ & 608 & $420(69)$ & $188(31)$ \\
\hline
\end{tabular}

${ }^{*}$ Comparison between the 2 groups of 1) percentage of patients positive for microemboli: $P=.005$ (for any microemboli), $P=.001$ (for solid microemboli); 2) absolute number of microemboli: $P=.001$ (for any microemboli), $P=.002$ (for solid microemboli); and 3) proportion of solid and gaseous microemboli: $P=$ NS. TComparison between the 2 groups of 1) percentage of patients positive for microemboli: $P=.0005$ (for any microemboli), $P<.0001$ (for solid microemboli); 2) absolute number of microemboli: $P<.001$ (both for any and solid microemboli), and 3) proportion of solid and gaseous microemboli: $P$

$=.05$. $\ddagger$ Comparison of percentage of bioprosthesis recipients positive for solid microemboli over time: $P=.01$.

platelet microparticles associated with a procoagulant activity in patients with prosthetic heart valves symptomatic for cerebrovascular events. Three years earlier, by monitoring antithrombotic treatments and coagulation markers, the same group $^{42}$ showed that microemboli are likely to be composed at least in part of platelets. Several other studies supported this hypothesis by demonstrating a decrease in
HITS after oral ${ }^{3}$ or intravenous ${ }^{3,24}$ administration of antiplatelet drugs. For example, Laas and colleagues ${ }^{24}$ found a $16 \%$ to $41 \%$ reduction with intravenously administered lysine acetylsalicylate. suggesting that particulate microemboli constituted a minority component. However, the most frequent method for demonstrating the likely gaseous nature of the majority of cerebral microemboli in prosthetic valve

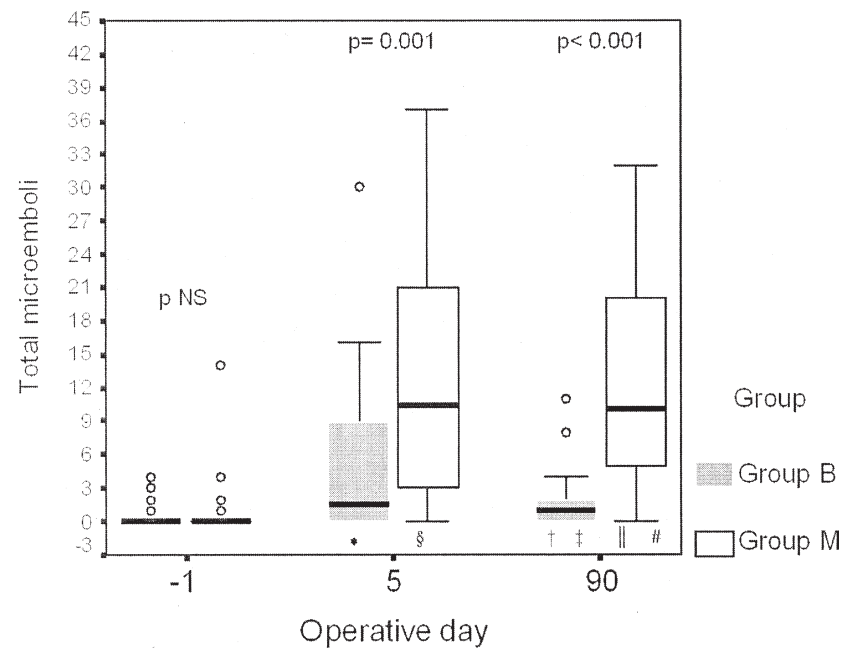

Figure 1. Median number (25th-75th percentile) of total microemboli in biologic (group B) and mechanical (group M) aortic valve prostheses recipients, as detected 1 day before $(-1)$ and 5 days (5) and 3 months (90) after isolated AVR. Comparison of number of total microemboli detected in group $B:{ }^{*} 1$ day before and 5 days after surgery $(P=.001) ;+1$ day before and 3 months after surgery $(P=.01) ; \neq 5$ days and 3 months after surgery $(P=.04)$. Comparison of number of total microemboli detected in group $\mathbf{M}$ : \$1 day before and 5 days after surgery $(P<.0001)$; $\| 1$ day before and 3 months after surgery $(P<.0002) ; \# 5$ days and 3 months after surgery $(P=.5)$. NS, Not significant.

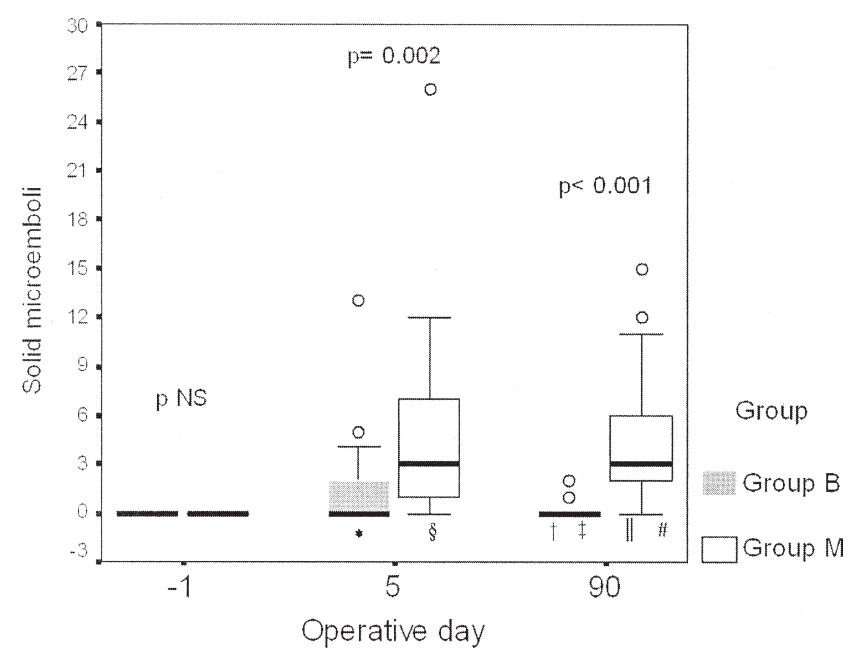

Figure 2. Median number (25th-75th percentile) of solid microemboli in biologic (group B) and mechanical (group M) aortic valve prostheses recipients, as detected 1 day before $(-1)$ and 5 days (5) and 3 months (90) after isolated AVR. Comparison of number of solid microemboli detected in group $B: * 1$ day before and 5 days after surgery $(P=.002) ; \dagger 1$ day before and 3 months after surgery $(\boldsymbol{P}=.06) ; \neq 5$ days and 3 months after surgery $(\boldsymbol{P}=$ .02). Comparison of number of solid microemboli detected in group M: $\$ 1$ day before and 5 days after surgery $(P<.0002) ; \| 1$ day before and 3 months after surgery $(P<.0003)$; \#5 days and 3 months after surgery $(P=.6)$. NS Not significant. 
TABLE 5. Variation in transcranially detected cerebral microembolic load and microemboli nature discrimination methods among different studies

\begin{tabular}{|c|c|c|c|c|}
\hline First author & $\begin{array}{l}\text { No. of patients (prosthesis type, } \\
\text { position) }\end{array}$ & $\begin{array}{l}\text { Time at recording } \\
\text { postoperatively } \\
\text { (recording duration) }\end{array}$ & HITS count/incidencet & $\begin{array}{l}\text { Methods for microemboli } \\
\text { nature discrimination }\end{array}$ \\
\hline Muller ${ }^{3}$ (1994) & 100 (mechanical; $\mathrm{A} / \mathrm{M} / \mathrm{A}+\mathrm{M})$ & $\begin{aligned} \leq & 3 \text { wk (50 patients) } \\
\geq & 12 \text { wk (50 patients) } \\
& (10 \text { min })\end{aligned}$ & $\begin{array}{l}-/ 54 \% \text { (total) } \\
-/ 66 \% \text { ( } \leq 3 \text { wk) } \\
-/ 42 \% \text { ( } \geq 12 w k)\end{array}$ & $\begin{array}{l}\text { Oral/IV antiplatelet } \\
\text { administration (7 } \\
\text { patients) }\end{array}$ \\
\hline Braekken ${ }^{4}$ (1995) & 92 (mechanical; A) & $\begin{array}{l}\text { Early ( } 36 \text { patients) } \\
12 \text { mo ( } 34 \text { patients) } \\
60 \text { mo ( } 22 \text { patients) } \\
\text { ( } 30 \text { min) }\end{array}$ & $\begin{array}{l}-/ 87 \% \text { (total) } \\
-/ 77.8 \% \text { (early) } \\
-/ 91.2 \%(12 \mathrm{mo}) \\
-/ 95.5 \%(60 \mathrm{mo})\end{array}$ & - \\
\hline Georgiadis $^{5}$ (1997) & 123 (mechanical; $\mathrm{A} / \mathrm{M} / \mathrm{A}+\mathrm{M}$ ) & $\begin{array}{c}17 \pm 1^{*} \text { mo } \\
\text { (45 min) }\end{array}$ & $-1>48 \%$ & $\begin{array}{l}100 \% \text { oxygen inhalation } \\
\text { (43 patients) }\end{array}$ \\
\hline Sliwka ${ }^{6}$ (1998) & $\begin{array}{l}580 \text { (mechanical/biological; } \\
\text { A/M/A+M) }\end{array}$ & $\begin{array}{c}15 \pm 1^{*} \mathrm{mo} \\
(30 \mathrm{~min})\end{array}$ & $\begin{array}{l}4.5(4-6) \ddagger / 65 \% \text { (total) } \\
0(0-1) \ddagger / 26 \% \text { (biological) } \\
6(5-7.5) \ddagger / 70 \% \text { (mechanical) }\end{array}$ & - \\
\hline Milano ${ }^{7}$ (1999) & $\begin{array}{l}83 \text { (mechanical/biological/ } \\
\text { homograft/mitral repair; } \\
\text { A/M/A+M) }\end{array}$ & $\begin{array}{l}\text { Discharge/3 mo/12 mo } \\
\quad(30 \mathrm{~min})\end{array}$ & $\begin{array}{l}55 \pm 79 \S / 30 \% \text { (total) } \\
-/ 85 \% \text { (mechanical) } \\
-/ 10 \% \text { (biological) } \\
-/ 0 \% \text { (homograft/mitral repair) }\end{array}$ & $\begin{array}{l}100 \% \text { oxygen inhalation } \\
\text { (12 patients) }\end{array}$ \\
\hline $\begin{array}{l}\text { Baumgartner } \\
\text { (2001) }\end{array}$ & 15 (mechanical; $\mathrm{A} / \mathrm{M} / \mathrm{A}+\mathrm{M}$ ) & $\begin{array}{l}\text { NA } \\
\qquad(30 \mathrm{~min})\end{array}$ & $20(12-78) \ddagger$ & Hyperbaric exposure \\
\hline $\begin{array}{l}\text { Uekermann } \\
\text { (2005) }\end{array}$ & 40 (mechanical; A) & $5.3^{*}$ y $(30 \mathrm{~min})$ & $\begin{array}{l}\text { 42-531\# (HITS-high group, } 21 \\
\text { patients) } \\
0 \text {-30\# (HITS-low group, } 19 \\
\text { patients) }\end{array}$ & - \\
\hline Grosset $^{10}(1994)$ & $\begin{array}{l}64 \text { (mechanical/biological; } \\
\text { A/M/A+M) }\end{array}$ & NA & $\begin{array}{l}-/ 72 \% \text { (total) } \\
-/ 88 \% \text { (mechanical) } \\
-/ 14 \% \text { (biological) }\end{array}$ & - \\
\hline Lievense $^{11}$ (1998) & 40 (mechanical/homograft; A) & $\begin{array}{l}\text { Outdoor patients } \\
\text { (30 min) }\end{array}$ & $\begin{array}{l}-/ 60 \% \text { (total) } \\
13(0-70) \| / 80 \% \text { (mechanical) } \\
3(0-18) \| / 40 \% \text { (homograft) }\end{array}$ & - \\
\hline Notzold $^{12}$ (1997) & $\begin{array}{l}17 \text { (mechanical/pulmonary } \\
\text { autograft; A) }\end{array}$ & $\begin{array}{l}\text { NA } \\
\text { (60 min, unilateral) }\end{array}$ & $\begin{array}{l}2-84 \# / 100 \% \text { (mechanical) } \\
12^{* *} / 25 \% \text { (pulmonary } \\
\text { autograft) }\end{array}$ & - \\
\hline $\mathrm{Kaps}^{21}$ (1997) & 5 (mechanical; A) & $\begin{array}{c}\geq 8 \mathrm{mo} \leq 60 \mathrm{mo} \\
(30 \mathrm{~min})\end{array}$ & $9(2-55) \|$ & $100 \%$ oxygen inhalation \\
\hline Kofidis $^{22}$ (2002) & 42 (mechanical; A) & $\begin{array}{l}\text { NA } \\
\text { (60 min) }\end{array}$ & $-/ 69 \%$ & - \\
\hline $\operatorname{Laas}^{24}(2003)$ & $\begin{array}{l}30 \text { (bileaflet prosthesis/tilting } \\
\text { disc prosthesis; A) }\end{array}$ & $\begin{array}{l}\geq 9 \mathrm{mo} \\
\quad(30 \mathrm{~min})\end{array}$ & $\begin{array}{l}\text { 32-108\# (bileaflet prosthesis) } \\
0-2 \# \text { (tilting disc prosthesis) }\end{array}$ & $\begin{array}{l}100 \% \text { oxygen inhalation/IV } \\
\text { antiplatelet } \\
\text { administration ( } 10 \\
\text { patients) }\end{array}$ \\
\hline Russell ${ }^{34}$ (2002) & 15 (mechanical; NA) & $\begin{array}{l}\text { NA } \\
\qquad(60 \mathrm{~min})\end{array}$ & $514^{* *}$ & $\begin{array}{l}\text { Multifrequency TCD } \\
6(5-7.5) \ddagger / 70 \% \text { (mechanical) } \\
\text { Systeme GmbH, Singen, } \\
\text { Germany) }\end{array}$ \\
\hline $\begin{array}{l}\text { Georgiadis }{ }^{36} \\
\text { (1998) }\end{array}$ & 10 (mechanical; $\mathrm{A} / \mathrm{M} / \mathrm{A}+\mathrm{M})$ & $\begin{array}{c}18 \pm 2^{*} \mathrm{mo} \\
(30 \mathrm{~min})\end{array}$ & $\begin{array}{l}112(75-175) \ddagger, \text { CCA } \\
30(18-36) \ddagger, M / A C A\end{array}$ & $\begin{array}{l}\text { HITS counts decline from } \\
\text { CCA to M/ACA }\end{array}$ \\
\hline $\begin{array}{l}\text { Georgiadis }{ }^{39} \\
\text { (1994) }\end{array}$ & 60 (mechanical; NA) & $\begin{array}{c}21 \pm 5^{*} \mathrm{mo} \\
(30 \mathrm{~min})\end{array}$ & $5958^{* *}$ & $\begin{array}{l}\text { Spectral analysis of emboli } \\
\text { signals }\end{array}$ \\
\hline Geiser $^{41}$ (1998) & 26 (mechanical; NA) & $5.2 \pm 4.6^{*}$ y $(30 \mathrm{~min})$ & $24(0-248)|| / 81 \%$ & $\begin{array}{l}\text { Flow cytometry with } \\
\text { platelet-specific } \\
\text { antibodies }\end{array}$ \\
\hline
\end{tabular}

HITS, High intensity transient signal; $A$, aortic position; $M$, mitral position; $A+M$, both aortic and mitral positions; NA, not available; $C C A$, common carotid artery; $M / A C A$, middle/anterior cerebral artery; $I V$, intravenous. ${ }^{*}$ Mean \pm standard deviation. TPercentage of patients positive for HITS. $\neq$ Median $(95 \%$ confidence intervals). §Mean \pm standard deviation of HITS per hour. ||Median (range). \#Range of HITS per hour. ${ }^{* *}$ Absolute number of HITS. 
recipients was the reduction in HITS counts during $100 \%$ oxygen inhalation: ${ }^{5,7,21,24,30}$ Milano and colleagues ${ }^{7}$ found a decrease in the number of HITS per hour from $55( \pm 79)$ to $22( \pm 31)$ after $100 \%$ oxygen; Droste and colleagues ${ }^{30}$ found a decrease in HITS in 20 patients with mechanical prosthetic cardiac valves from 144 HITS per hour without oxygen to 63 HITS per hour with oxygen. These studies actually suggested that approximately one third of the microemboli cannot be eliminated by $100 \%$ oxygen therapy and thus may be particulate. Our results are in agreement with these findings, and the comparison strengthens the importance of their results.

Because only indirect methods have been used in the literature to suggest that the nature of microemboli associated with valve prostheses may have a mixed composition, we believe our study to determine the exact proportion of solid and gaseous microemboli using a sophisticated newgeneration TCD is particularly valuable. As summarized in Table 5 , it can be seen that our results are broadly in line with the findings of previous studies ${ }^{6,7,10-12}$ in terms of the incidence of HITS with mechanical valves. However, an interesting finding is that we also found a far higher incidence of HITS in biological valves. This could be the result of an increased sensitivity or a decreased specificity of the technique used for the microemboli detection. Indeed, the automatic rejection of artifacts achievable with the EmboDop system reduces bias in the interpretation of HITS and avoids interobserver variability. The original "in vivo" validation of the current multirange and multifrequency TCD system was carried out by Russell and Brucher ${ }^{34}$ in a much smaller cohort of prosthetic heart valve recipients. The authors did not, however, compare mechanical and biological prostheses. More recently, Markus and Punter ${ }^{43}$ while confirming the superior discrimination achievable with this new Embo-Dop TCD system compared with conventional TCD ultrasound, reported it to have a sensitivity of only $50 \%$ but a specificity of $96 \%$ for detecting solid microemboli in vivo. If confirmed, that finding will only serve to emphasize the already significantly greater solid microembolic load detected with mechanical rather than biological prostheses. ${ }^{43}$ The suggestion that embolus detection and differentiation may be unreliable in situations with bursts of microemboli entering the sample volume at the same time $e^{44}$ is not likely to influence our current observations because the frequency of emboli generation was low. Finally, when all the technical parameters of the system (ie, Doppler signal enhancement) are satisfied, as in the current study, the dual-frequency Doppler can discriminate the nature of microemboli with reliable results. ${ }^{44}$

Although biological recipients were all receiving aspirin, mechanical recipients received warfarin without any antiplatelet agents. This could explain the reduction in the proportion of particulate microemboli over time in the bio- logical valve group but not in the mechanical group. Because the use of aspirin in addition to warfarin after mechanical valve replacement has been convincingly shown to reduce the incidence of thromboembolic events and death (the benefit was greater than the increased risk of bleeding), ${ }^{45,46}$ it would be interesting to examine HITS using aspirin as well as warfarin in the mechanical valve recipients.

It is tempting to speculate that the steady production of solid microemboli detected in mechanical prosthesis recipients during a 30-minute period, if extrapolated over many years, could clarify at least in part the pathologic mechanisms causing neurocognitive decline associated with chronic cerebral microembolisation in some studies, ${ }^{2,9,19}$ but other studies have found no such relationship., ${ }^{6,20-22}$ Zimpfer and colleagues ${ }^{47}$ initially reported immediate postoperative impairment of neuropsychologic outcome in patients with mechanical and biologic valves, but by 4 months the younger patients with mechanical valves had returned to normal (demonstrating a lack of a correlation between HITS and neuropsychologic outcome). In their 2006 article $^{48}$ the same group compared longer term (3 years) follow-up of mechanical AVR with age-matched nonsurgical controls and found no difference in neuropsychologic outcomes in the valve recipients, although these studies can be criticized for using only auditory-evoked P300 latencies as a neuropsychologic test.

\section{Limitations}

Although our study sought to determine the exact proportion of solid and gaseous microemboli, its major limitation is the lack of any associated cerebral outcome measurements (eg, neurocognitive testing or magnetic resonance imaging) and therefore uncertainty regarding the clinical significance of its findings.

Because this was not a randomized trial, it is possible that other differences between the 2 groups may have affected the HITS rate independently of valve type. However, as summarized in Tables 1 and 2, mechanical and biologic valve recipients were well matched for the main factors influencing the HITS rate, including myocardial contractility, heart rate, valve type and size, and method of valve implantation. However, the results could also be affected by the use of aspirin in the biologic valve group, which would explain the reduction of microemboli detected over time in group B but not in group M. Indeed, using aspirin instead of warfarin after a biological aortic valve implantation is the current practice among the majority of cardiac surgeons, and consequently our findings reflect a "real-world" situation.

Finally, because a number of different mechanical and biologic valves were used in each group, we cannot comment as to how prosthetic valve design in terms of bileaflet 
versus tilting disc for mechanical valves and stented versus stentless for bioprostheses influenced the results.

\section{Conclusions}

Solid cerebral microemboli represent approximately one third of the total cerebral microembolic load after mechanical AVR and are detectable in the majority of such patients both 5 days and 3 months after surgery.

The authors acknowledge Mr Ravi Pillai, Mr. Chandi Ratnatunga, and Mr Stephen Westaby for allowing us to study their patients.

\section{References}

1. Schumann H, Feigenbaum H, Dillon JC, Chang S. Intracavitary echoes in patients with prosthetic valves. J Clin Ultrasound. 1975;3:107-10.

2. Rams JJ, Davis DA, Lolley DM, Berger MP, Spencer M. Detection of microemboli in patients with artificial heart valves using transcranial Doppler: preliminary observations. J Heart Valve Dis. 1993;2:37-41.

3. Muller HR, Burckhardt D, Casty M, Pfisterer ME, Buser MW. High intensity transcranial Doppler signals (HITS) after prosthetic valve implantation. J Heart Valve Dis. 1994;3;602-6.

4. Braekken SK, Russell D, Brucher R, Svennevig J. Incidence and frequency of cerebral embolic signals in patients with a similar bileaflet mechanical heart valve. Stroke. 1995;26:1225-30.

5. Georgiadis D, Wenzel A, Lehmann D, Lindner A, Zerkowski HR, Zierz S, et al. Influence of oxygen ventilation on Doppler microemboli signals in patients with artificial heart valves. Stroke. 1997;28:218994.

6. Sliwka U, Georgiadis D. Clinical correlation of Doppler microembolic signals in patients with prosthetic cardiac valves- analysis of 580 cases. Stroke. 1998;29:140-3.

7. Milano A, D'Alfonso A, Codecasa R, De Carlo M, Nardi C, Orlandi $\mathrm{G}$, et al. Prospective evaluation of frequency and nature of transcranial high-intensity Doppler signals in prosthetic valve recipients. $J$ Heart Valve Dis. 1999;8:488-94.

8. Baumgartner RW, Frick A, Kremer C, Oechslin E, Russi E, Turina J, et al. Microembolic signal counts increase during hyperbaric exposure in patients with prosthetic heart valves. J Thorac Cardiovasc Surg. 2001;122:1142-6.

9. Uekermann J, Suchan B, Kseibi S, Perthel M, Laas J. Neuropsychological deficits after mechanical aortic valve replacement. $J$ Heart Valve Dis. 2005;14:338-43.

10. Grosset DG, Cowburn P, Georgiadis D, Dargie HJ, Faichney A, Lee KR. Ultrasound detection of cerebral microemboli in patients with prosthetic heart valves. J Heart Valve Dis. 1994;3:128-32.

11. Lievense AM, Bakker SL, Dippel DW, Taams MA, Koudstaal PJ, Bogers AJ. Intracranial high-intensity transient signals after homograft or mechanical aortic valve replacement. J Cardiovasc Surg (Torino). 1998;39:613-17.

12. Notzold A, Droste DW, Hagedorn G, Berndt S, Kaps M, Graf B, et al. Circulating microemboli in patients after aortic valve replacement with pulmonary autografts and mechanical valve prostheses. Circulation. 1997;96:1843-6.

13. Stump DA, Tegeler CH, Rogers AT, Coker LH, Newman SP, Wallenhaupt SL, et al. Neuropsychological deficits are associated with the number of emboli detected during cardiac surgery. Stroke. 1993;24: 509 (abstract presented to the 7th International Symposium on Cerebral Hemodynamics).

14. Pugsley W, Klinger L, Paschalis C, Treasure T, Harrison M, Newman S. The impact of microemboli during cardiopulmonary bypass on neuropsychological functioning. Stroke. 1994;25:1393-9.

15. Stump DA, Rogers AT, Hammon JW, Newman SP. Cerebral emboli and cognitive outcome after cardiac surgery. J Cardiothorac Vasc Anesth. 1996;10:113-9.
16. Sylivris S, Levi C, Matalanis G, Rosalion A, Buxton BF, Mitchell A, et al. Pattern and significance of cerebral microemboli during coronary artery bypass grafting. Ann Thorac Surg. 1998;66:1674-8.

17. Abu-Omar Y, Cifelli A, Matthews PM, Taggart DP. The role of microembolisation in cerebral injury as defined by functional magnetic resonance imaging. Eur J Cardiothorac Surg. 2004;26:586-91.

18. Abu-Omar Y, Cader S, Guerrieri Wolf L, Pigott D, Matthews PM, Taggart DP. Short-term changes in cerebral activity in on-pump and off-pump cardiac surgery defined by functional magnetic resonance imaging and their relationship to microembolization. $J$ Thorac Cardiovasc Surg. 2006;132:1119-25.

19. Deklunder G, Roussell M, Lecroart JL, Prat A, Gautier C. Microemboli in cerebral circulation and alteration of cognitive abilities in patients with mechanical prosthetic heart valves. Stroke. 1998;29: 1821-6.

20. Nadareishvili ZG, Beletsky V, Black SE, Fremes SE, Freedman M, Kurzman D, et al. Is cerebral microembolism in mechanical prosthetic heart valves clinically relevant? J Neuroimaging. 2002;12:310-15.

21. Kaps M, Hansen J, Weiher M, Tiffert K, Kayser I, Droste DW. Clinically silent microemboli in patients with artificial prosthetic aortic valves are predominantly gaseous and not solid. Stroke. 1997;28: $322-5$.

22. Kofidis T, Fischer S, Leyh R, Mair H, Deckert M, Haberl R, et al. Clinical relevance of intracranial high intensity transient signals in patients following prosthetic aortic valve replacement. Eur J Cardiothorac Surg. 2002;21:22-6.

23. MacKay TG, Georgiadis D, Grosset DG, Lees KR, Wheatley DJ. On the origin of cerebrovascular microemboli associated with prosthetic heart valves. Neurosci Res. 1995;17:349-52.

24. Laas J, Kseibi S, Perthel M, Klingbeil A, El-Ayoubi L, Alken A. Impact of high intensity transient signals on the choice of mechanical aortic valve substitutes. Eur J Cardiothorac Surg. 2003;23:93-6.

25. Georgiadis D, Kaps M, Berg J, MacKay TG, Dapper F, Faichney A, et al. Transcranial Doppler detection of microemboli in prosthetic heart valve patients: dependency upon valve type. Eur J Cardiothorac Surg. 1996;10:253-7.

26. Kleine P, Perthel M, Hasenkam JM, Nygaard H, Hansen SB, Laas J. Downstream turbulence and high intensity transient signals (HITS) following aortic valve replacement with Medtronic Hall or St. Jude Medical valve substitutes. Eur J Cardiothorac Surg. 2000;17:20-4.

27. Deklunder G, Lecroart JL, Conger JL, Lapeyre D, Gregoric I, Rose H, et al. Effects of myocardial contractility on microemboli production by mechanical heart valves in a bovine model. Tex Heart Inst J. 2000; 27:236-9.

28. Bluestein D, Li YM, Krukenkamp IB. Free emboli formation in the wake of bi-leaflet mechanical heart valves and the effects of implantation techniques. J Biomech. 2002;35:1533-40.

29. Hiratsuka R, Fukunaga S, Tayama E, Takagi K, Arinaga K, Shojima T, et al. High-intensity transient signals due to prosthetic valve obstruction: diagnostic and therapeutic implications. Ann Thorac Surg. 2004; 77:1615-21.

30. Droste DW, Hansberg T, Kemeny V, Hammel D, Schulte-Altedorneburg G, Nabavi DG, et al. Oxygen inhalation can differentiate gaseous from non gaseous microemboli detected by transcranial Doppler ultrasound. Stroke. 1997;28:2453-6.

31. Steinberg GK, De La Paz R, Mitchell SM, Bell TE, Albers GW. MRI and cerebrospinal fluid enzymes as sensitive indicators of subclinical cerebral injury after open-heart valve replacement surgery. Am $J$ Neuroradiol. 1996;17:205-12.

32. Hills BA, James PB. Microbubble damage to the blood-brain barrier: relevance to decompression sickness. Undersea Biomed Res. 1991;18: 111-6.

33. Brucher R, Russell D. Automatic online embolus detection and artifact rejection with the first multifrequency transcranial Doppler. Stroke. 2002;33:1969-74.

34. Russell D, Brucher R. Online automatic discrimination between solid and gaseous cerebral microemboli with the first multifrequency transcranial Doppler. Stroke. 2002;33:1975-80.

35. Laas J, Kleine P, Hasenkam MJ, Nygaard H. Orientation of tilting disc and bileaflet aortic valves substitutes for optimal hemodynamics. Ann Thorac Surg. 1999;68:1096-9. 
36. Georgiadis D, Baumgartner RW, Karatschai R, Lindner A, Zerkowski HR. Further evidence of gaseous embolic material in patients with artificial heart valves. J Thorac Cardiovasc Surg. 1998;115:808-10.

37. Dauzat M, Deklunder G, Aldis A, Rabinovitch R, Burte F, Bret PM. Gas bubble emboli detected by transcranial Doppler sonography in patients with prosthetic heart valves: a preliminary report. J Ultrasound Med. 1994;13;129-35.

38. Georgiadis D, Mallinson A, Grosset DG, Lees KR. Emboli signals and coagulation activity in patients with prosthetic heart valves. Stroke. 1994;25:1211-4.

39. Georgiadis D, MacKay TG, Kelman AW, Grosset DG, Wheatley DJ, Lees KR. Differentiation between gaseous and formed embolic materials in vivo. Application in prosthetic heart valve patients. Stroke. 1994;25:1559-63.

40. Raco L, Belcher PR, Sim I, McGarrity A, Bernacca GM, Wheatley DJ. Platelet aggregation and high intensity transient signals (HITS) in a sheep model of mitral valve replacement. J Heart Valve Dis. 1999;8; 476-81.

41. Geiser T, Sturzenegger M, Genewein U, Haeberli A, Beer JH. Mechanisms of cerebrovascular events as assessed by procoagulant activity, cerebral microemboli, and platelet microparticles in patients with prosthetic heart valves. Stroke. 1998;29:1770-7.
42. Sturzenegger M, Beer JH, Rihs F. Monitoring combined antithrombotic treatments in patients with prosthetic heart valves using transcranial Doppler and coagulation markers. Stroke. 1995;26:63-9.

43. Markus HS, Punter M. Can transcranial Doppler discriminate between solid and gaseous microemboli? Assessment of a dual-frequency transducer system. Stroke.2005;36:1731-4.

44. Russell D, Brucher R. Embolus detection and differentiation using multifrequency transcranial Doppler. Stroke. 2005;36:706.

45. Turpie AG, Gent M, Laupacis A, Latour Y, Gunstensen J, Basile F, et al. A comparison of aspirin with placebo in patients treated with warfarin after heart-valve replacement. $N$ Engl J Med. 1993;329: 524-9.

46. Little SH, Massel DR. Antiplatelet and anticoagulation for patients with prosthetic heart valves. Cochrane Database Syst Rev. 2003: CD003464.

47. Zimpfer D, Kilo J, Czerny M, Kasimir MT, Madl C, Bauer E, et al. Neurocognitive deficit following aortic valve replacement with biological/mechanical prosthesis. Eur J Cardiothorac Surg. 2003;23:54451.

48. Zimpfer D, Czerny M, Schuch P, Fakin R, Madl C, Wolner E, et al. Long- term neurocognitive function after mechanical aortic valve replacement. Ann Thorac Surg. 2006;81:29-33. 